\title{
Association of the S2 allele of the Sstl polymorphism in the apoC3 gene with plasma apoCIII interacts with unfavorable lipid profiles to contribute to atherosclerosis in the Li ethnic group in China
}

\author{
Minzeng Sun ${ }^{1,2+}$, Lin Chen ${ }^{1,2+}$, Hui Liu ${ }^{3}$, Lihui Ma², Tiansong Wang ${ }^{2}$ and Yueli Liu ${ }^{1 *}$ (D)
}

\begin{abstract}
Background: The Sstl polymorphism in the apolipoprotein 3 gene (apoC3) has been identified in many ethnic groups. In addition, the S2 allele of the Sstl polymorphism is shown to be associated with increased plasma triglyceride (TG) levels. Plasma apoCIII is an important atherogenic factor, which interrupts lipid metabolism and is positively associated with plasma TG levels. However, the existence of the Sstl polymorphism in the Li ethnic group in China remains to be confirmed. The relationship between the S2 allele of the Sstl polymorphism and plasma apoCIII or TG and their roles in atherosclerosis are also unknown.
\end{abstract}

Methods: A cohort of 628 participants was recruited (316 atherosclerotic patients and 312 healthy controls) from both the Li and Han ethnic groups. Blood samples were obtained to evaluate the Sstl polymorphism in the apoC3 and lipid profiles. Chi-squared and $t$-tests and multiple unconditional logistic regression were employed to analyze the genotypic and allelic frequencies and lipid profiles using SPSS version 20.0 software.

Results: The Sstl polymorphism in the apoC3 was identified in the Li ethnic group. The S2 allele and plasma apoCIII and TG levels were associated with the development of atherosclerosis $(P<0.01$, S2 allele and apoCIII; $P<0.05, T G)$ in the Li ethnic group. The S2 allele was associated with increased plasma apoCIII levels in the atherosclerotic group $(P<0.01$ ), but with increased plasma apoCIII and TG levels in control group (both $P<0.01$ ). In addition to the increases in the S2 allele frequency and plasma TG and apoCIII levels, atherosclerotic patients in the Li ethnic group also exhibited increased apoB, decreased HDL-C and apoAl and a lower apoAl:apoB ratio (all $P<0.01$ ).

Conclusions: Our results indicate that the S2 allele of the Sstl polymorphism in the apoC3 gene is associated with plasma apoCIII levels in the Li population. In combination with unfavorable lipid profiles, this might contribute to susceptibility to atherosclerosis.

Keywords: S2 allele, ApoCIII, Atherosclerosis

\footnotetext{
* Correspondence: ly|20041981@126.com

${ }^{\dagger}$ Equal contributors

'Department of Pharmacology, School of Pharmacy, Hainan Medical

University, Haikou, Hainan Province 571199, China

Full list of author information is available at the end of the article
} 


\section{Background}

Several polymorphisms of the apolipoprotein C3 gene (apoC3) have been reported, the SstI polymorphism being the most well-known [1-3]. This polymorphism is defined as a $\mathrm{C}$ to $\mathrm{G}$ conversion in the $3^{\prime}$ untranslated region of exon 4 in the apoC3 [4], and has been confirmed to exist in several ethnic groups, including African American, Caucasian, Taiwanese and Chinese populations. There are two alleles of the SstI polymorphism: S1 and S2. Several studies have shown that the rare S2 allele is associated with increased plasma triglyceride (TG) levels, although this association is not always concordant among different ethnic groups [5-7].

The $\mathrm{Li}$ population is the smallest minority ethnic group in China, who reside predominantly in Hainan Province, which is not part of Mainland China. However, the existence of the SstI polymorphism in the apoC3 and the relationship between the $\mathrm{S} 2$ allele and plasma TG remain to be confirmed in the Li ethnic group.

Plasma TG is an atherogenic factor that plays a crucial role in the development of atherosclerosis [8-10]. Previous studies have shown that plasma apoCIII is also an independent risk factor for atherosclerosis, and the suppression of apoCIII is associated with decreased risks of atherosclerosis and coronary heart disease (CHD) [1114]. Plasma apoCIII is also associated with plasma TG $[3,4,6,7]$; however, the effects of the S2 allele on the risk of atherosclerosis and the relationships between the S2 allele and plasma levels of TG or apoCIII remain to be clarified in the Li ethnic group.

In this study, we investigated the existence of the Sst I polymorphism in the apoC3 in the $\mathrm{Li}$ ethnic group. We also investigated the relationships between the S2 allele and plasma TG or apoCIII levels and their roles in the development of atherosclerosis.

\section{Methods}

\section{Study population}

This study was approved by the Ethics Committee of the First Affiliated Hospital of Hainan Medical University (Hainan Province, China). Written informed consent was obtained from all subjects and the investigations were carried out in accordance with the principles of the Declaration of Helsinki. From September 2012 to September 2014, a total of 628 subjects were selected randomly from the $\mathrm{Li}$ and Han populations to attend our study. This group included 316 atherosclerotic subjects (AS), consisting of $155 \mathrm{Li}$ individuals and 161 Han individuals with an average age of $(63.68 \pm 12.19 y)$. In addition, 312 healthy subjects (control) were selected consisting of $158 \mathrm{Li}$ individuals and 154 Han individuals with an average age of $(61.75 \pm 13.07 \mathrm{y})$. The age range of the participants was between 41 and $88 \mathrm{y}$. There was no consanguinity among the participants, whose grandparents and parents were from the same population and resided in Hainan Province. Atherosclerotic subjects were determined by angiographic or ultrasonic detection of atherosclerotic plaques in the carotid or coronary arteries. Patients with a history of inflammatory disease, autoimmune disease, malignant tumors, familial hyperlipidemia or diabetes were excluded. Healthy subjects were screened on the basis of having no history of hypertension, cardiovascular or cerebral disease, and endocrine disease.

\section{Epidemiological survey}

An international standard method was applied to survey demographics, socioeconomic status, and lifestyle using a standardized questionnaire to gather and record all information. Smoking status and alcohol status were categorized into two groups: non-smoker and smoker, and non-drinker and drinker. The physical examination included measurements of body height, body weight, waist circumference, blood pressure, electrocardiograms, and body mass index (BMI). Blood pressure referred to the average sitting blood pressure after three measurements made using a mercurial sphygmomanometer. Systolic and diastolic blood pressures referred to the first and the fifth Korotkoff sounds, respectively. BMI was calculated by dividing weight $(\mathrm{kg})$ by squared height $\left(\mathrm{m}^{2}\right)$. Abdominal obesity was defined as waist circumference $\geq 90 \mathrm{~cm}$ for males and $\geq 85 \mathrm{~cm}$ for females. Overweight was defined as BMI $\geq 25 \mathrm{~kg} / \mathrm{m}^{2}$, and hypertension was diagnosed according to diagnostic criteria based on Chinese Guidelines for Prevention and Treatment of Dyslipidemia in Adults and the 2010 Chinese Guidelines for Prevention and Treatment of Hypertension.

\section{Biochemical analysis}

Venous fasting blood samples $(10 \mathrm{ml})$ were obtained after a $12 \mathrm{~h}$ overnight fast. From this sample, $6 \mathrm{ml}$ was used for analysis of the serum levels of TG, total cholesterol (TC), low density lipoprotein cholesterol (LDL-C), high density lipoprotein cholesterol (HDL-C), lipoprotein AI (apoAI), lipoprotein B (apoB), apoCIII, lipoprotein a [Lp(a)] and fasting blood sugar (FBS). The remaining $4 \mathrm{ml}$ was placed into a tube coated with the anticoagulant ethylene diamine tetra-acetic acid (EDTA) for extraction of deoxyribonucleic acid (DNA). TG, TC, HDL-C, LDL-C, and FBS levels were determined using enzymatic methods; and apoAI, apoB and Lp(a) were assessed using immunoturbidimetric assays with commercially available kits according to the manufacturer's instructions (Pointe Biotech, China). ApoCIII was measured by enzyme-linked immunosorbent assay (Abcam, Cambridge, England). All samples were processed using an autoanalyzer (Type 7600; Hitachi Ltd., Tokyo, Japan) or ELISA plate reader (Biotech, USA) at the First Affiliated Hospital of Hainan Medical University. 
Table 1 Demographic characteristics of atherosclerotic patients (AS) and healthy controls (control) in the Li and Han ethnic groups

\begin{tabular}{|c|c|c|c|c|}
\hline Characteristic & AS $(n=316)$ & Control $(n=312)$ & $t\left(x^{2}\right)$ & $P$-value \\
\hline Nationality (Li/Han) & $155 / 161$ & $158 / 154$ & 0.159 & 0.690 \\
\hline Sex (male/female) & $176 / 140$ & $150 / 162$ & 3.651 & 0.056 \\
\hline Age (years) & $63.68 \pm 12.19$ & $61.75 \pm 13.07$ & 1.908 & 0.057 \\
\hline Height (m) & $1.65 \pm 0.06$ & $1.64 \pm 0.06$ & 1.778 & 0.076 \\
\hline Weight (kg) & $65.49 \pm 7.35$ & $64.61 \pm 7.32$ & 1.511 & 0.131 \\
\hline $\mathrm{BMI}\left(\mathrm{kg} / \mathrm{m}^{2}\right)$ & $24.12 \pm 2.24$ & $24.06 \pm 2.33$ & 0.313 & 0.755 \\
\hline Non-smoker/smoker & $217 / 99$ & $235 / 77$ & 3.441 & 0.064 \\
\hline Non-drinker/drinker & $255 / 61$ & $232 / 80$ & 3.621 & 0.057 \\
\hline Waist circumference $(\mathrm{cm})$ & $83.14 \pm 3.94^{* *}$ & $75.34 \pm 5.41$ & 20.618 & 0.000 \\
\hline Systolic pressure (mmHg) & $139.85 \pm 22.05^{* *}$ & $133.27 \pm 11.51$ & 4.698 & 0.000 \\
\hline Diastolic pressure $(\mathrm{mmHg})$ & $81.93 \pm 11.65^{*}$ & $80.28 \pm 7.35$ & 2.118 & 0.035 \\
\hline
\end{tabular}

Data represent mean \pm SD. BMI: Body mass index, ${ }^{*} P<0.05,{ }^{* *} P<0.01$, atherosclerotic patients versus healthy controls analyzed using $X^{2}$-tests or $t$-tests

\section{DNA amplification and genotyping}

DNA was extracted from leukocytes present in the anticoagulant-treated blood sample using a DNA extracting kit (Sigma-Aldrich, USA). Restriction fragment length polymorphism (RFLP) analysis was employed to detect the SstI polymorphism in the apoC3 gene. The apoC3 gene was amplified by polymerase chain reaction (PCR) using the following primers: forward 5'-CATGGTTGCCTACAGAGGAGTTC-3' and reverse 5'-TTTGACCTTCCGCACAA AGCTGT-3' (Sangon, Shanghai, China) in a total volume containing: $10 \mu \mathrm{l}$ (300 ng) of template DNA, $2 \mu \mathrm{l}$ of each primer, $13.5 \mu \mathrm{l}$ of $2 \times$ EcoTaq PCR SuperMix, and $22.5 \mu \mathrm{l}$ of RNase-Free water. The amplification process was optimized using a $\mathrm{T}$ Gradient Thermocycler (Biometra, Germany) with an initial denaturation at $94{ }^{\circ} \mathrm{C}$ for $2 \mathrm{~min}$, followed by 35 cycles of denaturation at $95{ }^{\circ} \mathrm{C}$ for $1 \mathrm{~min}$, annealing at $56.2{ }^{\circ} \mathrm{C}$ for $45 \mathrm{~s}$, and extension at $72{ }^{\circ} \mathrm{C}$ for $1 \mathrm{~min}$, with a

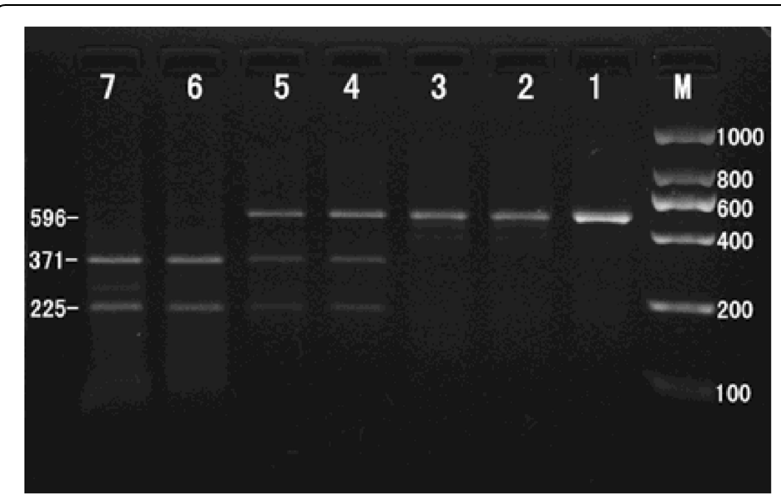

Fig. 1 Genotyping of the Sstl polymorphism in the apoC3 gene by RFLP of PCR amplification products. Lane M, 2000 bp ladder marker; Lane 1, PCR product amplified from blood samples (596 bp); Lanes 2 and 3, S1S1 genotype (596 bp); Lanes 4 and 5, S1S2 genotype (596 bp, 371 bp, 225 bp); Lanes 6 and 7, S2S2 genotype (371 bp, 225 bp) final extension at $72{ }^{\circ} \mathrm{C}$ for $10 \mathrm{~min}$. The amplification products were then subjected to RFLP analysis in a total reaction volume of $25 \mu \mathrm{l}$ consisting of $10 \mu \mathrm{l}$ of amplified DNA, $2.5 \mu \mathrm{l}$ of $10 \times$ NEB buffer, $1 \mu$ l of SstI restriction enzyme and $11.5 \mu \mathrm{l}$ of $\mathrm{ddH}_{2} \mathrm{O}$ at $37^{\circ} \mathrm{C}$ for $4 \mathrm{~h}$.

\section{DNA sequencing}

The S1S1, S1S2 and S2S2 genotypes identified by PCR-RFLP were also verified by DNA sequencing of both strands using the BigDye Terminator v3.1 Cycle Sequencing Kit (Applied Biosystems, Forster City, CA, USA) and an ABI 3730xl DNA Analyzer (Applied Biosystems).

\section{Statistical analysis}

Statistical analysis was carried out using SPSS version 20.0 software, and data were presented as mean \pm standard deviation (SD). Quantitative values were analyzed by $t$-test. Observed genotypic frequencies were compared to expected genotypic frequencies to assess Hardy-Weinberg equilibrium. The allele frequency of the SstI polymorphism in the apoC3 was determined by gene counting, and the chi-squared test was employed to test differences between the genotypic and allelic frequencies of the atherosclerotic patients and healthy controls in both the Li and Han ethnic groups. Differences in demographic characteristics were assessed by the chi-squared or $t$-tests. Multiple unconditional logistic regression analysis was employed to evaluate the effects of the SstI polymorphism in the apoC3 on the risk of atherosclerosis. Differences in the lipid profiles among the different genotypes were evaluated by $t$-test (intergroup comparisons of serum lipid profiles were performed with the Kruskal-Wallis test or the WilcoxonMann-Whitney test). $P$-values $<0.05$ were considered to indicate statistical significance. 


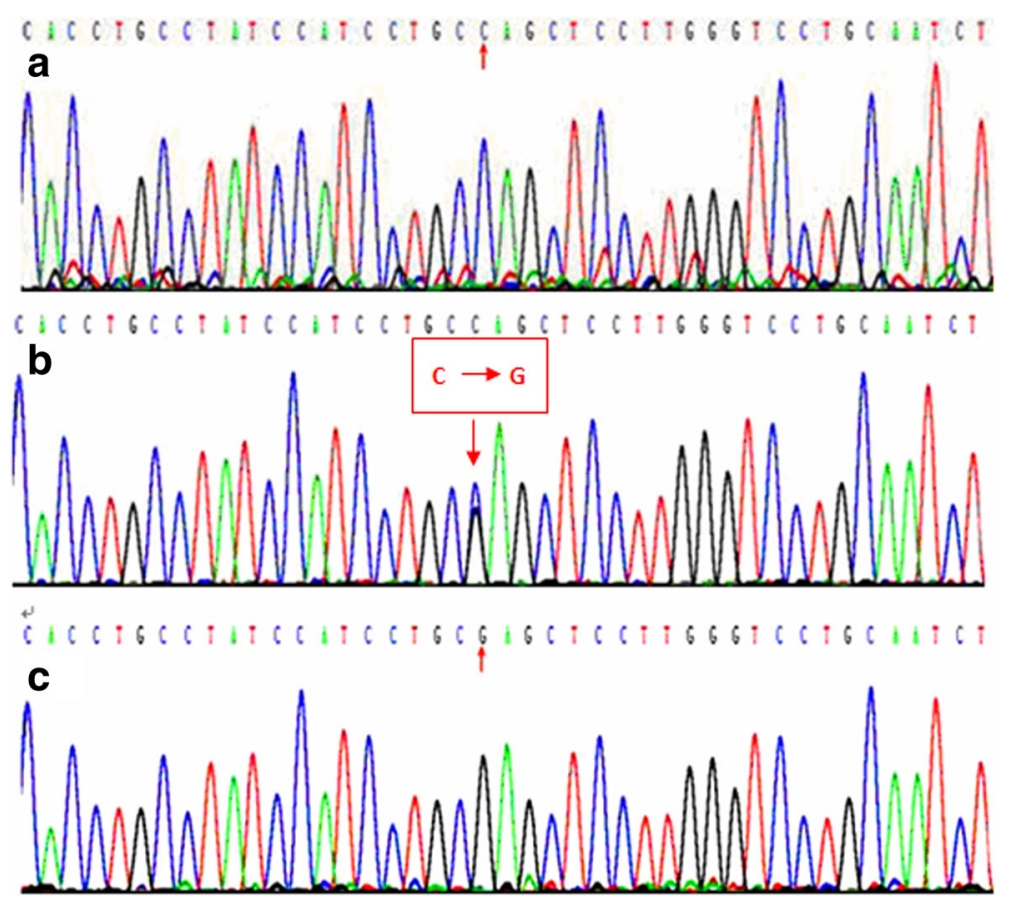

Fig. 2 Genotyping of the Sstl polymorphism in the apoC3 gene by DNA sequencing. a S1S1 genotype (CC); b S1S2 genotype (CG); c S2S2 genotype (GG)

\section{Results}

\section{Demographic characteristics of atherosclerotic patients and healthy subjects}

There were no significant differences between the Li and Han populations included in the study in terms of the male:female ratio, mean age, height and body weight, BMI, smoking status and drinking status (all $P>0.05$ ). Atherosclerotic subjects exhibited greater waist circumference and higher systolic and diastolic blood pressures than healthy subjects $(P<0.01$, waist circumference and systolic pressure; $P<0.05$, diastolic pressure) (Table 1 ).

Table 2 Hardy-Weinberg equilibrium of the genotype distributions of atherosclerotic patients (AS) and healthy controls (control)

\begin{tabular}{|c|c|c|c|c|c|c|}
\hline \multirow[t]{2}{*}{ Group } & & \multicolumn{3}{|c|}{$\begin{array}{l}\text { Frequency of different } \\
\text { genotypes }(n, \%)\end{array}$} & \multirow[t]{2}{*}{$x^{2}$} & \multirow[t]{2}{*}{$P$-value } \\
\hline & & S1S1 & S1S2 & $\mathrm{S} 2 \mathrm{~S} 2$ & & \\
\hline \multirow[t]{2}{*}{$\overline{A S}$} & $\begin{array}{l}\text { Actual } \\
\text { frequency }\end{array}$ & $\begin{array}{l}165 \\
(52.2)\end{array}$ & $\begin{array}{l}129 \\
(40.8)\end{array}$ & $\begin{array}{l}22 \\
(7.0)\end{array}$ & 0.070 & 0.966 \\
\hline & $\begin{array}{l}\text { Theoretical } \\
\text { frequency }\end{array}$ & $\begin{array}{l}167 \\
(52.8)\end{array}$ & $\begin{array}{l}126 \\
(39.9)\end{array}$ & $\begin{array}{l}23 \\
(7.3)\end{array}$ & & \\
\hline \multirow[t]{2}{*}{ Control } & $\begin{array}{l}\text { Actual } \\
\text { frequency }\end{array}$ & $\begin{array}{l}239 \\
(76.6)\end{array}$ & $64(20.5)$ & $9(2.9)$ & 0.997 & 0.608 \\
\hline & $\begin{array}{l}\text { Theoretical } \\
\text { frequency }\end{array}$ & $\begin{array}{l}235 \\
(75.3)\end{array}$ & 71 (22.8) & $6(1.9)$ & & \\
\hline
\end{tabular}

Data are expressed as numbers and percentages. Actual frequency versus theoretical frequency within atherosclerotic patients and healthy controls analyzed using $X^{2}$ tests
Determination of the Sstl polymorphism in the apoC3 gene Samples were genotyped on the basis of SstI RFLP analysis of PCR amplification products (Fig. 1). A single 596 bp fragment indicated homozygosity for the absence of Sst I restriction sites; this was defined as the S1S1 genotype (CC). Fragments of $596 \mathrm{bp}, 371 \mathrm{bp}$ and $225 \mathrm{bp}$ indicated heterozygosity for the presence and absence of SstI restriction sites; this was defined as the S1S2 genotype (CG). Fragments of $371 \mathrm{bp}$ and 225 bp indicated homozygosity for the presence of SstI restriction sites; this was defined as the S2S2 genotype (GG). Genotypes were confirmed by DNA sequencing (Fig. 2).

Table 3 Genotypic and allelic frequencies among atherosclerotic patients (AS) and healthy controls (control)

\begin{tabular}{|c|c|c|c|c|c|c|}
\hline \multirow[t]{2}{*}{ Group } & \multirow[t]{2}{*}{$n$} & \multicolumn{3}{|c|}{$\begin{array}{l}\text { Genotypic } \\
\text { frequencies }(n, \%)\end{array}$} & \multicolumn{2}{|c|}{$\begin{array}{l}\text { Allelic } \\
\text { frequencies }(n, \%)\end{array}$} \\
\hline & & $\overline{S 1 S 1}$ & S1S2 & $\mathrm{S} 2 \mathrm{~S} 2$ & S1 & S2 \\
\hline$\overline{\mathrm{AS}}$ & 316 & $165(52.2)$ & $129(40.8)^{* *}$ & $22(7.0)^{* *}$ & $459(72.6)$ & $173(27.4)^{* *}$ \\
\hline Control & 312 & $239(76.6)$ & 64 (20.5) & $9(2.9)$ & $542(86.9)$ & $82(13.1)$ \\
\hline$x^{2}$ & & 40.873 & & & 19.734 & \\
\hline$P$-value & & 0.000 & & & 0.000 & \\
\hline
\end{tabular}

Data are expressed as numbers and percentages. ${ }^{* *} P<0.01$, atherosclerotic patients versus healthy controls analyzed using $\chi^{2}$ tests 
Genotypic and allelic frequencies in atherosclerotic patients and healthy controls

The genotype frequencies of the atherosclerotic patients and healthy controls were in Hardy-Weinberg equilibrium $(P>0.05)$ (Table 2$)$. However, there were significantly higher frequencies of the S1S2 and S2S2 genotypes among the atherosclerotic patients compared with those among the healthy controls (both $P<0.01$ ). Furthermore, the frequency of the $\mathrm{S} 2$ allele was higher in atherosclerotic patients compared with that in the healthy controls $(P<$ 0.01) (Table 3). Further analysis revealed identical patterns in the $\mathrm{Li}$ and Han ethnic groups (Table 4).

Multiple unconditional logistic regression analysis of the effects of SStl polymorphism in the apoC3 gene on the risk of atherosclerosis

In multiple unconditional logistic regression analysis, atherosclerosis was used as the dependent variable (atherosclerosis: yes $=1$, no $=0$ ), while the independent variables were as follows: age $(\geq 50=1,<50=0)$, smoking (yes $=1$, no $=0$ ), drinking (yes $=1$, no $=0$ ), BMI $(\geq 25=$ $1,<25=0$ ), apoC3 genotype (S1S1 = 0, S1S2 or S2S2=1). According to the results, the S1S2 and S2S2 apoC3 genotypes were associated with a 2 -fold increase in the risk of atherosclerosis (Table 5), indicating that the S2 allele contributes to susceptibility to atherosclerosis.

\section{Lipid profiles of atherosclerotic and healthy participants} in the $\mathrm{li}$ and Han ethnic groups

FBS, TG, TC, LDL-C, apoB and apoCIII levels were significantly higher in atherosclerotic subjects compared to those in healthy controls, while HDL-C and apoAI levels and the apoAI:apoB ratio were significantly lower (all $P<0.01$ ). There was no significant difference in $\operatorname{Lp}(\mathrm{a})$ levels $(P>0.05)$ between atherosclerotic patients and healthy controls (Table 6). Further analysis revealed differences in the lipid profiles of the $\mathrm{Li}$ and $\mathrm{Han}$ ethnic groups. Although

Table 4 Genotypic and allelic frequencies in the Li and Han ethnic groups

\begin{tabular}{|c|c|c|c|c|c|c|c|}
\hline \multirow[t]{2}{*}{$\begin{array}{l}\text { Ethnic } \\
\text { group }\end{array}$} & \multirow[t]{2}{*}{ Group } & \multirow[t]{2}{*}{$n$} & \multicolumn{3}{|c|}{$\begin{array}{l}\text { Genotypic } \\
\text { frequencies (n, \%) }\end{array}$} & \multicolumn{2}{|c|}{$\begin{array}{l}\text { Allelic } \\
\text { frequencies (n, \%) }\end{array}$} \\
\hline & & & S1S1 & S1S2 & S2S2 & $S 1$ & S2 \\
\hline \multirow[t]{4}{*}{$\overline{\mathrm{Li}}$} & AS & 155 & $82(52.9)$ & $67(43.2)^{* *}$ & $6(3.9)^{* *}$ & $231(74.5)$ & $79(25.5)^{* *}$ \\
\hline & Control & 158 & $122(77.2)$ & $33(20.9)$ & $3(1.9)$ & $277(87.7)$ & 39 (12.3) \\
\hline & $x^{2}$ & & 20.376 & & & 17.699 & \\
\hline & $P$-value & & 0.000 & & & 0.000 & \\
\hline \multirow[t]{4}{*}{ Han } & AS & 161 & 83 (51.6) & $62(38.5)^{* *}$ & $16(9.9)^{* *}$ & $228(70.8)$ & $94(29.2)^{* *}$ \\
\hline & Control & 154 & $117(76.0)$ & $31(20.1)$ & $6(3.9)$ & $265(86.0)$ & $43(14.0)$ \\
\hline & $x^{2}$ & & 20.513 & & & 21.462 & \\
\hline & $P$-value & & 0.000 & & & 0.000 & \\
\hline
\end{tabular}

Data are expressed as numbers and percentages. ${ }^{* *} P<0.01$, atherosclerotic patients versus healthy controls in the $\mathrm{Li}$ and Han ethnic groups analyzed using $x^{2}$ tests
Table 5 The effects of SStl polymorphism in the apoC3 gene on the risk of atherosclerosis

\begin{tabular}{lccccc}
\hline Variable & AS (n) & Control (n) & Adjusted OR & $95 \% \mathrm{Cl}$ & $\begin{array}{c}\text { Adjusted } \\
\text { P-value }\end{array}$ \\
\hline Li ethnicity & & & & & \\
ApoC3 & & & & & \\
genotype & & & & & \\
S1S1 & 82 & 122 & 1 & & \\
S1S2 + S2S2 & 73 & 36 & 2.461 & $(1.545-3.919)$ & $<0.01$ \\
Han ethnicity & & & & & \\
ApoC3 & & & & & \\
genotype & & 117 & 1 & & \\
S1S1 & 83 & 37 & 2.899 & $(1.790-4.694)$ & $<0.01$ \\
S1S2 + S2S2 & 78 & 37 & & & \\
\hline
\end{tabular}

The model was adjusted for age, body mass index, smoking status and drinking status. OR: odds ratio, $\mathrm{Cl}$ : confidence interval. S1S1 genotype versus S1S2 + S2S2 genotype in the Li and Han ethnic groups analyzed using multivariate unconditional logistic regression analysis

increased TG, apoB, and apoCIII levels and decreased HDL-C levels were found in both ethnic groups, the apoAI levels and apoAI:apoB ratio were lower among atherosclerotic patients in the Li ethnic group (both $P<0.01$ ) in comparison to those of Han descent, who typically showed increased TC and LDL-C levels and a high apoAI:apoB ratio (all $P<0.01$ ) (Table 7).

Lipid profiles of S1 and S2 allele carriers among the atherosclerotic patients and healthy controls in the li and Han ethnic groups

In the Li ethnic group, S2 allele carriers exhibited increased plasma apoCIII levels compared to those of S1 allele carriers among the atherosclerotic patients $(P<0.01)$, while the S2

Table 6 Lipid profiles of atherosclerotic patients (AS) and healthy controls (control)

\begin{tabular}{lllll}
\hline Parameter & AS $(n=316)$ & Control $(n=312)$ & $t$ & $P$-value \\
\hline FBS $(\mathrm{mmol} / \mathrm{L})$ & $5.88 \pm 1.30^{* *}$ & $5.67 \pm 0.48$ & 2.795 & 0.005 \\
$\mathrm{TC}(\mathrm{mmol} / \mathrm{L})$ & $5.08 \pm 1.10^{* *}$ & $4.77 \pm 0.80$ & 4.087 & 0.000 \\
$\mathrm{TG}(\mathrm{mmol} / \mathrm{L})$ & $1.44 \pm 1.01^{* *}$ & $1.15 \pm 0.66$ & 4.245 & 0.000 \\
$\mathrm{HDL}-\mathrm{C}(\mathrm{mmol} / \mathrm{L})$ & $1.12 \pm 0.37^{* *}$ & $1.27 \pm 0.32$ & -5.443 & 0.000 \\
$\mathrm{LDL}-\mathrm{C}(\mathrm{mmol} / \mathrm{L})$ & $3.16 \pm 0.90^{* *}$ & $2.83 \pm 0.73$ & 4.984 & 0.000 \\
ApoAl $(\mathrm{g} / \mathrm{L})$ & $1.20 \pm 0.36^{* *}$ & $1.28 \pm 0.34$ & -2.964 & 0.003 \\
ApoB $(\mathrm{g} / \mathrm{L})$ & $1.03 \pm 0.23^{* *}$ & $0.87 \pm 0.18$ & 9.418 & 0.000 \\
ApoAl / ApoB & $1.24 \pm 0.50^{* *}$ & $1.54 \pm 0.53$ & -7.226 & 0.000 \\
Lp(a) $(\mathrm{mg} / \mathrm{L})$ & $250.02 \pm 183.39$ & $227.80 \pm 168.16$ & 1.583 & 0.114 \\
ApoCIII $(\mathrm{mg} / \mathrm{dL})$ & $16.36 \pm 6.20^{* *}$ & $10.95 \pm 4.45$ & 12.576 & 0.000 \\
\hline
\end{tabular}

Data are expressed as mean \pm SD. FBS: Fasting blood sugar; TC: Total cholesterol; TG: Triglyceride; HDL-C: High density lipoprotein cholesterol; LDL-C: Low density lipoprotein cholesterol; ApoAl: Lipoprotein Al; ApoB: Lipoprotein B; Lp(a): Lipoprotein a; ApoCIII: Apolipoprotein CIII; ${ }^{* *} \mathrm{P}<0.01$, atherosclerotic patients versus healthy controls analyzed using $t$-tests 
Table 7 Comparison of lipid profiles of atherosclerotic patients (AS) and healthy controls (control) in the Li and Han ethnic groups

\begin{tabular}{|c|c|c|c|c|c|c|}
\hline \multirow[t]{2}{*}{ Parameter } & \multicolumn{3}{|l|}{ Li ethnicity } & \multicolumn{3}{|l|}{ Han ethnicity } \\
\hline & AS $(n=155)$ & Control $(n=158)$ & $P$-value & AS $(n=161)$ & Control $(n=154)$ & $P$-value \\
\hline TC (mmol/L) & $5.12 \pm 1.29$ & $4.99 \pm 0.76$ & 0.273 & $5.04 \pm 0.89^{* *}$ & $4.54 \pm 0.77$ & 0.000 \\
\hline TG (mmol/L) & $1.34 \pm 0.78^{*}$ & $1.18 \pm 0.59$ & 0.039 & $1.54 \pm 1.18^{* *}$ & $1.13 \pm 0.73$ & 0.000 \\
\hline $\mathrm{HDL}-\mathrm{C}(\mathrm{mmol} / \mathrm{L})$ & $1.20 \pm 0.40^{* *}$ & $1.33 \pm 0.29$ & 0.002 & $1.04 \pm 0.34^{* *}$ & $1.21 \pm 0.33$ & 0.000 \\
\hline LDL-C (mmol/L) & $3.10 \pm 1.02$ & $2.90 \pm 0.73$ & 0.058 & $3.22 \pm 0.78^{* *}$ & $2.76 \pm 0.73$ & 0.000 \\
\hline ApoAl (g/L) & $1.28 \pm 0.41^{* *}$ & $1.39 \pm 0.34$ & 0.009 & $1.12 \pm 0.29$ & $1.17 \pm 0.31$ & 0.150 \\
\hline ApoB (g/L) & $0.96 \pm 0.24^{* *}$ & $0.84 \pm 0.16$ & 0.000 & $1.11 \pm 0.24^{* *}$ & $0.89 \pm 0.19$ & 0.000 \\
\hline ApoAl/ApoB & $1.40 \pm 0.55^{* *}$ & $1.70 \pm 0.52$ & 0.000 & $1.09 \pm 0.21^{* *}$ & $0.90 \pm 0.19$ & 0.000 \\
\hline Lp (a) (mg/L) & $238.4 \pm 161.4$ & $225.3 \pm 152.8$ & 0.460 & $247.9 \pm 176.6$ & $232.8 \pm 165.5$ & 0.434 \\
\hline ApoCIII (mg/dL) & $15.83 \pm 6.12^{* *}$ & $11.49 \pm 4.51$ & 0.000 & $16.87 \pm 6.25^{* *}$ & $10.39 \pm 4.34$ & 0.000 \\
\hline
\end{tabular}

Data are expressed as mean \pm SD. TC: Total cholesterol; TG: Triglyceride; HDL-C: High density lipoprotein cholesterol; LDL-C: Low density lipoprotein cholesterol; ApoAl: Lipoprotein Al; ApoB: Lipoprotein B; Lp(a): Lipoprotein a; ApoCIII: Apolipoprotein CIII; $P<0.05,{ }^{* *} P<0.01$, atherosclerotic patients versus healthy controls in the $\mathrm{Li}$ and Han ethnic groups analyzed using $t$-tests

allele carriers showed increased TG and apoCIII levels among the healthy controls $(P<0.01 ; P<0.05)$ (Table 8$)$. In the Han ethnic group, S2 allele carriers exhibited increased TG levels compared to S1 allele carriers among the atherosclerotic patients, while S2 allele carriers showed increased plasma apoCIII levels among the healthy controls $(P<0.01)$ (Table 9).

\section{Discussion}

Our study confirmed the existence of the SstI polymorphism in the apoC3 gene in the $\mathrm{Li}$ ethnic group, with increased frequencies of the S1S2 and S2S2 genotypes and the $\mathrm{S} 2$ allele found in atherosclerotic patients. Furthermore, the S2 allele was associated with an increased risk of atherosclerosis.

The S2 allele, unfavorable lipid profiles (increased FBS, TG, TC, LDL-C, apoB, and apoCIII; decreased HDL-C, apoAI and lower apoAI:apoB ratio) and environmental risk factors, such as elevated waist circumference and increased systolic and diastolic pressure were found to promote the development of atherosclerosis. We identified variations in these results when we investigated lipid profiles and the roles they played in atherosclerosis susceptibility in the $\mathrm{Li}$ and Han ethnic groups. According to our results, the S2 allele was consistently associated with plasma apoCIII in the $\mathrm{Li}$ population, while the association with plasma TG existed only in the healthy controls in this ethnic group. Based on the association of apoCIII with TG reported in a previous study [10,15-17], we speculate that apoCIII might represent a link between the S2 allele and plasma TG levels, although this was not the only parameter which affected plasma TG, especially in the presence of atherosclerosis. In the Han population, the S2 allele was associated with increased plasma TG levels in the atherosclerotic group and with increased plasma apoCIII levels in the healthy controls. The variation in the association of the S2 allele with

Table 8 Lipid profiles between S1 allele carriers and S2 allele carriers in the Li ethnic group

\begin{tabular}{|c|c|c|c|c|c|c|}
\hline \multirow[t]{2}{*}{ Parameter } & \multicolumn{3}{|l|}{ AS $(n=155)$} & \multicolumn{3}{|c|}{ Control $(n=158)$} \\
\hline & S1S1 $(n=82)$ & $S 1 S 2+S 2 S 2(n=73)$ & $P$-value & S1S1 $(n=122)$ & $\mathrm{S} 1 \mathrm{~S} 2+\mathrm{S} 2 \mathrm{~S} 2(n=36)$ & $P$-value \\
\hline $\mathrm{TC}(\mathrm{mmol} / \mathrm{L})$ & $5.12 \pm 1.32$ & $5.13 \pm 1.29$ & 0.956 & $4.95 \pm 0.78$ & $5.12 \pm 0.72$ & 0.259 \\
\hline TG (mmol/L) & $1.26 \pm 0.63$ & $1.43 \pm 0.92$ & 0.166 & $1.07 \pm 0.44$ & $1.53 \pm 0.84^{* *}$ & 0.003 \\
\hline $\mathrm{HDL}-\mathrm{C}(\mathrm{mmol} / \mathrm{L})$ & $1.26 \pm 0.42$ & $1.14 \pm 0.36$ & 0.064 & $1.33 \pm 0.29$ & $1.32 \pm 0.29$ & 0.982 \\
\hline $\mathrm{LDL}-\mathrm{C}(\mathrm{mmol} / \mathrm{L})$ & $3.03 \pm 0.99$ & $3.17 \pm 1.05$ & 0.405 & $2.90 \pm 0.72$ & $2.91 \pm 0.77$ & 0.917 \\
\hline ApoAl (g/L) & $1.29 \pm 0.43$ & $1.26 \pm 0.39$ & 0.644 & $1.41 \pm 0.36$ & $1.33 \pm 0.26$ & 0.243 \\
\hline ApoB (g/L) & $0.94 \pm 0.22$ & $0.98 \pm 0.26$ & 0.260 & $0.85 \pm 0.16$ & $0.83 \pm 0.15$ & 0.610 \\
\hline ApoAl/ApoB & $1.44 \pm 0.58$ & $1.36 \pm 0.52$ & 0.362 & $1.72 \pm 0.53$ & $1.66 \pm 0.49$ & 0.569 \\
\hline $\mathrm{Lp}(\mathrm{a})(\mathrm{mg} / \mathrm{L})$ & $254.0 \pm 168.1$ & $218.8 \pm 156.3$ & 0.181 & $231.5 \pm 164.1$ & $208.0 \pm 101.3$ & 0.298 \\
\hline ApoCIII (mg/dL) & $14.07 \pm 5.21$ & $17.81 \pm 6.48^{* *}$ & 0.000 & $10.90 \pm 3.96$ & $13.53 \pm 5.60^{*}$ & 0.012 \\
\hline
\end{tabular}

Data are expressed as mean \pm SD. TC: Total cholesterol; TG: Triglyceride; HDL-C: High density lipoprotein cholesterol; LDL-C: Low density lipoprotein cholesterol; ApoAl: Lipoprotein Al; ApoB: Lipoprotein B; Lp(a): Lipoprotein a; ApoCIII: Apolipoprotein CIII; $P<0.05,{ }^{* *} P<0.01$, S1 allele carriers versus S2 allele carriers in the Li ethnic group analyzed using the Kruskal-Wallis or Wilcoxon-Mann-Whitney tests 
Table 9 Lipid profiles in S1 allele carriers and S2 allele carriers in the Han ethnic group

\begin{tabular}{|c|c|c|c|c|c|c|}
\hline \multirow[t]{2}{*}{ Parameter } & \multicolumn{3}{|l|}{ AS $(n=151)$} & \multicolumn{3}{|c|}{ Control $(n=154)$} \\
\hline & S1S1 $(n=83)$ & $S 1 S 2+S 2 S 2(n=78)$ & $P$-value & S1S1 $(n=117)$ & $\mathrm{S} 1 \mathrm{~S} 2+\mathrm{S} 2 \mathrm{~S} 2(n=37)$ & $P$-value \\
\hline TC (mmol/L) & $4.92 \pm 0.79$ & $5.18 \pm 0.97$ & 0.065 & $4.52 \pm 0.77$ & $4.60 \pm 0.78$ & 0.622 \\
\hline TG $(\mathrm{mmol} / \mathrm{L})$ & $1.27 \pm 0.54$ & $1.84 \pm 1.56^{* *}$ & 0.003 & $1.06 \pm 0.53$ & $1.36 \pm 1.13$ & 0.122 \\
\hline $\mathrm{HDL}-\mathrm{C}(\mathrm{mmol} / \mathrm{L})$ & $1.08 \pm 0.37$ & $0.99 \pm 0.29$ & 0.117 & $1.23 \pm 0.36$ & $1.14 \pm 0.25$ & 0.089 \\
\hline LDL-C (mmol/L) & $3.17 \pm 0.73$ & $3.28 \pm 0.82$ & 0.389 & $2.76 \pm 0.74$ & $2.77 \pm 0.70$ & 0.895 \\
\hline ApoAl (g/L) & $1.11 \pm 0.29$ & $1.13 \pm 0.29$ & 0.682 & $1.15 \pm 0.31$ & $1.24 \pm 0.29$ & 0.097 \\
\hline ApoB (g/L) & $1.07 \pm 0.21$ & $1.10 \pm 0.21$ & 0.266 & $0.97 \pm 0.20$ & $0.86 \pm 0.17$ & 0.291 \\
\hline ApoAl/Apo B & $1.10 \pm 0.42$ & $1.10 \pm 0.34$ & 0.522 & $1.33 \pm 0.52$ & $1.48 \pm 0.43$ & 0.111 \\
\hline $\mathrm{Lp}(\mathrm{a})(\mathrm{mg} / \mathrm{L})$ & $244.6 \pm 159.4$ & $251.4 \pm 194.2$ & 0.806 & $222.3 \pm 152.8$ & $265.8 \pm 199.3$ & 0.164 \\
\hline ApoCIII (mg/dL) & $15.97 \pm 5.89$ & $17.83 \pm 6.51$ & 0.059 & $9.78 \pm 3.87$ & $12.32 \pm 5.15^{* *}$ & 0.008 \\
\hline
\end{tabular}

Data are expressed as mean \pm SD. TC: Total cholesterol; TG: Triglyceride; HDL-C: High density lipoprotein cholesterol; LDL-C: Low density lipoprotein cholesterol; ApoAl: Lipoprotein Al; ApoB: Lipoprotein B; Lp(a): Lipoprotein a; ApoCIII: Apolipoprotein CIII; ${ }^{* *}<0.01$, S1 allele carriers versus S2 allele carriers in the Han ethnic group analyzed using the Kruskal-Wallis or Wilcoxon-Mann-Whitney tests

plasma TG or apoCIII levels indicated the importance of our study. The S2 allele and elevation of either plasma apoCIII or TG were found to be associated with the development of atherosclerosis in both the $\mathrm{Li}$ and Han ethnic groups. The SstI polymorphism in the apoC3 gene was also shown to influence the risk of atherosclerosis. In contrast, a recent study showed that non-mutated apoC3 gene carriers exhibited a favorable lipid profile, and revealed strong genetic evidence implicating the S2 allele in the development of atherosclerosis $[18,19]$.

Our study revealed the association of the S2 allele with plasma apoCIII levels, which combined with unfavorable lipid profiles and environmental risk factors, contributed to the development of atherosclerosis in the $\mathrm{Li}$ ethnic group. Thus, it can be hypothesized that ApoCIII functions as a link between the S2 allele and plasma TG levels, although the exact mechanism of the interactions among the S2 allele and the levels of plasma apoCIII and TG remain to be clarified.

\section{Conclusions}

The association of the S2 allele of the SstI polymorphism in the apoC3 gene with plasma apoCIII levels interacts with unfavorable lipid profiles to contribute to the development of atherosclerosis in the Li population in China.

\section{Abbreviations \\ ApoAl: Lipoprotein Al; ApoB: Lipoprotein B; ApoCIII: Apolipoprotein CIII; BMI: Body mass index; CHD: Coronary heart disease; DNA: Deoxyribonucleic acid; EDTA: Ethylene diamine tetra-acetic acid; ELISA: Enzyme-linked immunosorbent assay; FBS: Fasting blood sugar; HDL-C: High density lipoprotein cholesterol; IDL: Intermediate density lipoprotein; LDL: Low density lipoprotein; LDL-C: Low density lipoprotein cholesterol; Lp(a): Lipoprotein a; PCR: Polymerase chain reaction; RFLP: Restriction fragment length polymorphism; TC: Total cholesterol; TG: Triglyceride; THP-1: Human acute monocytic leukemia cell line; VLDL: Very low density lipoprotein}

\section{Acknowledgments}

We would like to thank Dr. Mr. Mengsen Li PHD and Ms. Jun Ma for critical review of the manuscript, and Mr. Yunbo Zhang for help in collecting samples. Thanks also go to all participants who made the study possible.
Funding

The study was sponsored by the National Natural Science Foundation of China (No 81260060) and the Natural Science Foundation of Hainan Province (No 30726), China.

\section{Availability of data and materials}

All data generated or analyzed during this study were included in this published article.

\section{Authors' contributions}

$Y L$ conceived and designed the study. MS and LC performed the experiments. LC analyzed the data. HL, LM and TW contributed reagents/ materials/analysis tools. YL wrote the paper. All authors read and approved the final manuscript.

\section{Ethics approval and consent to participate}

All procedures were conducted in accordance with the ethical standards of the responsible committee on human experimentation (institutional and national) and with Helsinki Declaration of 1975, as revised in 2008.This study was approved by the Ethnic Committee of the First Affiliated Hospital of Hainan Medical University. Informed consent was obtained from all participants.

Consent for publication

Not applicable.

\section{Competing interests}

The authors declare that they have no competing interests.

\section{Publisher's Note}

Springer Nature remains neutral with regard to jurisdictional claims in published maps and institutional affiliations.

\section{Author details}

${ }^{1}$ Department of Pharmacology, School of Pharmacy, Hainan Medical University, Haikou, Hainan Province 571199, China. ${ }^{2}$ Department of Cardiology, People's Hospital of Sanya, Sanya, Hainan Province 572000, China. ${ }^{3}$ Department of Anatomy, School of Basic Medicine and Life Sciences, Hainan Medical University, Haikou, Hainan Province 571199, China.

Received: 28 June 2017 Accepted: 14 November 2017

Published online: 21 November 2017

\section{References}

1. Masana L, Febrer G, Cavanna J, Baroni MG, Marz W, Hoffmann MM, Shine B, Galton DJ. Common genetic variants that relate to disorders of lipid transport in Spanish subjects with premature coronary artery disease [j]. Clin Sci (Lond). 2001;100(2):183-90.

2. Souverein OW, Jukema JW, Boekholdt SM, Zwinderman AH, Tanck MW. Polymorphisms in APOA1 and LPL genes are statistically independently 
associated with fasting TG in men with CAD [J]. Eur J Hum Genet. 2005; 13(4):445-51.

3. Su S, Tang M, Zhang M, Cheng C, Tang X. The relationship between apolipoprotein CIII gene polymorphism and serum lipid levels in Han Chinese males. Meta Gene. 2013;15(1):58-64.

4. Yiyang L, Ruixing Y, Meng L, Kela L, Xingjiang L, Lin Z, Wanying L, Shangling P, Dezhai Y, Weixiong L. Apolipoprotein C-III gene polymorphism and several environmental factors with serum lipid levels in the Guangxi Hei Yi Zhuang and Han populations. J Investig Med. 2010;58(6):777-85.

5. Lee JY, Hong HR, Kang HS. Ethnicity differences in plasma apoC-III levels between African American and Caucasian youths. World J Pediatr. 2011;7(2): $136-42$

6. Huang MC, Wang TN, Liu YL, Pa TH, Tu HP, Huang YC, Chang WT, Ko YC. Effect of Sstl polymorphism of the apolipoprotein CIII gene and Environmental factors on risks of hypertriglyceridemia in Taiwan aborigines. Circ J. 2006;70(8):1030-6.

7. Johansen CT, Wang J, Lanktree MB, Martins RA, Ban MR, Lanktree MB, Huff MW, Péterfy M, Mehrabian M, Lusis AJ, et al. Excess of rare variants in genes identified by genome-wide association study of hypertriglyceridemia. Nat Genet. 2010;42:684-7.

8. Johansen $C T$, Hegele RA. Allelic and phenotypic spectrum of plasma triglycerides. Biochim Biophys Acta. 2012;1821(5):833-42.

9. Wang J, Ban MR, Zou GY, Cao H, Lin T, Kennedy BA, Anand S, Yusuf S, Huff MW, Pollex RL, et al. Polygenic determinants of severe hypertriglyceridemia. Hum Mol Genet. 2008;17:2894-9.

10. Petersen KF, Dufour S, Hariri A, Nelson-Williams C, Foo JN, Zhang XM, Dziura J, Lifton RP, Shulman Gl. Apolipoprotein C3 gene variants in nonalcoholic fatty liver disease. N Engl J Med. 2010;362:1082-9.

11. Mendivil CO, Rimm EB, Furtado J, Chiuve SE, Sacks FM. Low-density lipoproteins containing apolipoprotein C-III and the risk of coronary heart disease. Circulation. 2011;124(19):2065-72.

12. Mendivil CO, Rimm EB, Furtado J, Sacks FM, Apolipoprotein E. In VLDL and LDL with apolipoprotein C-III is associated with a lower risk of coronary heart disease. J Am Heart Assoc. 2013;2(3):e000130.

13. Murray W. Huff, Robert a. Hegele. Apolipoprotein C-III going back to the future for a lipid drug target. Circ Res. 2013;112:1405-8

14. Shin MJ, Krauss RM, Apolipoprotein CIII. Bound to apoB-containing lipoproteins is associated with small, dense LDL independent of plasma triglyceride levels in healthy men. Atherosclerosis. 2010;211(1):337-41.

15. Ehx G, Gérin S, Mathy G, Franck F, Oliveira HC, Vercesi AE, Sluse FE. Liver proteomic response to hypertriglyceridemia in human-apolipoprotein C-III transgenic mice at cellular and mitochondrial compartment levels. Lipids Health Dis. 2014;13:116.

16. Graham MJ, Lee RG, Bell TA 3rd, Fu W, Mullick AE, Alexander VJ, Singleton W, Viney N, Geary R, Su J, et al. Antisense oligonucleotide inhibition of apolipoprotein C-III reduces plasma triglycerides in rodents, nonhuman primates, and humans. Circ Res. 2013;112:1479-90.

17. Wang F, Kohan AB, Dong HH, Yang Q, Xu M, Huesman S, Lou D, Hui DY, Tso P. Overexpression of apolipoprotein C-III decreases secretion of dietary triglyceride into lymph. Physiol Rep. 2014;2(3):e00247.

18. Pollin Tl, Damcott CM, Shen H, Ott SH, Shelton J, Horenstein RB, Post W, McLenithan JC, Bielak LF, Peyser PA, et al. A null mutation in human APOC3 confers a favorable plasma lipid profiles and apparent cardioprotection. Science. 2008;322(5908):1702-5.

19. Desroches S, Ruel IL, Deshaies Y, Paradis ME, Archer WR, Couture P, Bergeron N, Lamarche B. Kinetics of plasma apolipoprotein C-III as a determinant of diet-induced changes in plasma triglyceride levels. Eur J Clin Nutr. 2008;62(1):10-7.

\section{Submit your next manuscript to BioMed Central and we will help you at every step:}

- We accept pre-submission inquiries

- Our selector tool helps you to find the most relevant journal

- We provide round the clock customer support

- Convenient online submission

- Thorough peer review

- Inclusion in PubMed and all major indexing services

- Maximum visibility for your research

Submit your manuscript at www.biomedcentral.com/submit
) Biomed Central 